\title{
Fotografias do cotidiano de mulheres: uma experiência pelas lentes de uma terapeuta ocupacional $^{1}$
}

\author{
Carine Abrahão Rodrigues Assis, Flávia Liberman, Viviane Santalucia Maximino \\ Universidade Federal de São Paulo - UNIFESP, São Paulo, SP, Brasil.
}

\begin{abstract}
Resumo: Introdução: O termo "Cotidiano" é importante para o campo da terapia ocupacional como conceito estruturante de sua construção teórica e prática. Refere-se ao detalhamento da vida humana, na sua dimensão de qualidade das relações entre o sujeito e os seus fazeres. Este artigo relata uma pesquisa-intervenção realizada com mulheres na região noroeste da cidade de Santos, na qual, utilizando a fotografia, buscamos maneiras de conhecer e intervir em seus cotidianos. Objetivo: Experimentar e discutir as potencialidades da fotografia como recurso de compreensão e de intervenção no dia a dia de mulheres que vivem em situação de vulnerabilidade. Método: Realizamos uma pesquisa-intervenção com o recurso da autofotografia, por meio de três encontros com duas mulheres distintas. Utilizamos a entrevista semiestruturada e os diários de campo para produção de dados. Resultados: A exploração do cotidiano por meio da fotografia possibilitou conhecer minúcias e meandros que tornam a rotina diária única para cada sujeito e que se expressam nos gestos, desejos e arranjos de forma singular. Conclusão: A fotografia demonstrou ser um recurso de avaliação e de intervenção que promove a experiência relacional, sensorial e afetiva, além de ampliar as percepções sobre a vida tanto das mulheres abordadas quanto das pesquisadoras.
\end{abstract}

Palavras-chave: Terapia Ocupacional, Fotografia, Atividades Cotidianas.

\section{Pictures of women's daily life: an experience through the lens of an occupational therapist}

\begin{abstract}
Introduction: The term "Daily Life" is important to the field of occupational therapy as a structural concept of its theoretical and practical construction. It refers to the details of human life in its dimension of quality of relations between the subject and their doings. This paper reports an intervention research conducted with women in the northwest region of the city of Santos in which, by means of photographs, we sought ways of knowing and intervening in their daily lives. Objective: To experience and discuss photography capabilities as a resource to understand and intervene in the day-to-day activities of women living in situations of vulnerability in the northwest of the city of Santos. Method: The research-intervention was performed with the use of self-photography through three meetings with two different women. Semi-structured interviews and a field diary were used for data collection. Results: The exploration of the daily life through photographs allowed knowing the details and intricacies that make the daily routine unique for each person and that are expressed in gestures, wishes and arrangements in a unique way. Conclusion: Photography proved to be a resource of evaluation and intervention that promotes relational, sensory and affective experiences and expands the perceptions of life of both women and researchers.
\end{abstract}

Keywords: Occupational Therapy, Photography, Activities of Daily Living.

Autor para correspondência: Carine Abrahão Rodrigues Assis, Universidade Federal de São Paulo, Edifício Central, Rua Silva Jardim, 136, CEP 11015-020, Santos, SP, Brasil, e-mail: carineabrahao@hotmail.com

Recebido em Jun. 4, 2016; $1^{\text {a }}$ Revisão em Set. 26, 2016; 2a Revisão em Nov. 21, 2016; Aceito em Dez. 5, 2016. 


\section{Introdução}

O sujeito se constrói no dia a dia, a partir de suas relaçôes com o ambiente, trabalho, família, entre outras dimensôes. Essa construção é dinâmica, característica do que é vivo, e compóe uma teia complexa que se desdobra e se articula. A essa matéria, de que é feita a vida de cada um e de todos nós, chamamos de Cotidiano $^{2}$. Considerando que o termo "Cotidiano" diz respeito à relação que os sujeitos constroem com seus fazeres no encontro com os corpos humanos e não humanos, no uso e na passagem do tempo, interessa ao terapeuta ocupacional a pergunta: como você passa seu dia a dia? (MAXIMINO; TEDESCO, 2016). Essa pergunta não é banal e deve ser considerada em toda sua espessura, pois, epistemologicamente, compóe, com outros elementos, o campo da terapia ocupacional, indicando, por exemplo, sua população-alvo, a qual, consideramos aquela que apresenta uma característica genérica descrita como uma dificuldade para fazer aquilo que deseja ou precisa fazer, o que, geralmente, causa isolamento, falta ou dificuldade de participação social. Essa descrição é propositalmente genérica para abarcar as inúmeras possibilidades de atuação de terapeutas ocupacionais.

Neste caso, atendemos a essa população a partir de um projeto de extensão denominado Cartografias femininas: açóes territoriais junto às mulheres na regiáo noroeste de Santos ${ }^{3}$. Todas as mulheres vivem em situação de vulnerabilidade, pois são idosas ou estão sem trabalho, têm dificuldades de obter sua subsistência, têm uma rede de suporte social restrita, estão doentes ou com mobilidade reduzida, encontram-se em sofrimento psíquico etc. Buscamos maneiras de conhecer e intervir utilizando a fotografia para participar e produzir novas perspectivas em seus cotidianos. Esse processo produziu reflexóes e evidenciou o uso da fotografia como uma ferramenta potente na pesquisa-intervenção.

\subsection{Mulheres, cotidianos e vulnerabilidade}

Soares (2007) cita que as desigualdades sociais afetam, especialmente, as mulheres, com reflexos sobre a sua saúde. Ao traçarmos uma linha histórica sobre os papéis da mulher ao longo dos séculos, podemos perceber como as diversas transformaçôes sociais incidem sobre o seu dia a dia. Kujawski refere-se a uma crise, que ele chama de crise do cotidiano:

A crise do século XX não é, primariamente, crise dos fundamentos da ciência, ou da política, ou da economia, ou do que for, e sim crise dos fundamentos da vida humana. E, como a vida humana se constitui, imediatamente, como cotidianidade, a origem da crise deve ser investigada na quebra dos padróes da vida cotidiana durante o século $\mathrm{XX}$, principalmente em sua segunda metade [...] (KUJAWSKI, 1991, p. 34).

A mulher, apesar de conquistar equiparaçóes e direitos, não se eximiu de seus "deveres" de cuidar da casa, da educação e participação na vida dos filhos, acrescentando papéis em sua vida e gerando um acúmulo de tarefas que a sobrecarrega e, muitas vezes, leva ao adoecimento (FRANÇA; SHIMANSKI, 2009). Soma-se a isso a vulnerabilidade social que deve ser considerada não só em seu aspecto individual, mas também contextual e coletivo, tais como: a pobreza, as diferenças socioeconômicas, a quebra de vínculos familiares, afetivos, de participação na sociedade, culturais, educativos, a falta de conhecimento dos direitos e deveres, entre outros (OSÓRIO, 2015).

Sendo assim, afirmamos a necessidade de intervenções que possam dar vez e voz a essas mulheres, por vezes silenciadas em situaçóes de opressão de diversas ordens: cultural, econômica e subjetiva.

\subsection{Fotografando o cotidiano}

O fotografar possui um sentido de eternizar. Uma imagem, ao ser produzida, não está mais só ao acaso da lembrança, mas sim presente todos os dias em que for contemplada. Podemos dizer que a fotografia que se destaca é aquela que produz "[...] exatamente o contrário do estupor; antes uma agitação interior, uma festa, um trabalho também, a pressão do indizível que quer se dizer" (BARTHES, 1980, p. 35). Nesse sentido, a fotografia não é apenas um fim, mas um meio de transformar e produzir outras realidades.

Colecionar fotografias é colecionar o mundo (SONTAG, 1981), um convite para olhar aquilo que nos é conhecido de uma nova maneira, com a possibilidade de produzir deslocamentos. Fotografar cotidianos é um modo de poder observar, com delicadeza e singularidade, territórios existenciais ${ }^{4}$, declarando o interesse em imprimir um olhar único e em encontrar tempos e modos singulares de existência. Acolher toda experiência como única, em contraposição à padronização rotineira, é acolher a expressão da singularidade (LIBERMAN, 2008), compreendendo por Cotidiano esta matéria composta das relaçóes entre a rotina, os hábitos, as condições materiais e culturais da vida (MAXIMINO; TEDESCO, 2016). 
Quando utilizado em pesquisas, o recurso fotográfico pode ter várias funçóes, que incidem sobre as técnicas e as proposiçóes feitas aos participantes. Para Neiva-Silva e Koller (2002), uma primeira função é a de registro, para documentar determinada ocorrência. Nesta, a ideia é a aproximação a certa realidade espaço-temporal ${ }^{5}$. Na segunda função, de mobilização de determinada temática, são apresentadas fotografias aos participantes relacionadas a algum tema, ligado ao objeto de estudo, mas que não retratam os próprios participantes. Outra possibilidade é o uso da fotografia como um instrumento de feedback, quando o participante da pesquisa é anteriormente avaliado em determinado aspecto, depois fotografado por terceiros em diferentes circunstâncias, e o resultado é apresentado posteriormente a ele. E, em uma última função, temos a chamada autofotografia, quando cada participante recebe uma câmera fotográfica e é solicitado que fotografe para responder a alguma questão, de acordo com instruçóes recebidas previamente. Dessas categorias, a autofotografia foi considerada a mais adequada ao projeto, pois a intenção da pesquisa era captar a percepção de cada sujeito sobre seu próprio cotidiano.

O objetivo inicial da pesquisa foi verificar a potencialidade da fotografia como recurso para conhecer o cotidiano das mulheres convidadas. No decorrer da pesquisa, observamos que o ato de fotografar tornou-se ele mesmo uma intervenção, pois era composto pelo contato com a pesquisadora, que estava intimamente implicada nesse processo, e a proposição de uma atividade, o fotografar, configurando uma relação triádica entre pesquisadora-terapeuta ocupacional, sujeito-alvo e atividade (BENETTON, 2006).

\section{Método}

A pesquisa caracteriza-se como pesquisa-intervenção, tendo como norteador o conceito trazido por Barros e Kastrup (2010), em que o pesquisador investiga uma hipótese em campo e também atua sob ele em contato direto com as pessoas e seus territórios existenciais. Trata-se de uma pesquisa qualitativa, que permite a aproximação à realidade, estabelecendo uma interação com os atores que a conformam, construindo um conhecimento empírico (MINAYO, 2001).

\subsection{Participantes e cenário}

Para a realização da pesquisa, contamos com a participaçáo de duas mulheres que chegaram ao projeto de extensão por indicaçóes de serviços da região (NAPS I, Arte no Dique e PSF Jardim
Castelo $)^{6}$, nos quais se realiza o Módulo de Trabalho em Saúde da Baixada Santista ${ }^{7}$. Ao longo de quatro meses de pesquisa, foram contatadas cinco mulheres que participavam desses projetos, entretanto apenas duas aceitaram participar da pesquisa. As mulheres foram entrevistadas em suas casas e realizaram as fotografias tanto nesse ambiente quanto em outros, com e sem a presença da pesquisadora.

\subsection{Instrumentos de produção dos dados $^{8}$}

Segundo Araújo et al. (2013), ao admitir-se que a pesquisa sofra alterações no seu desenvolvimento, o registro em diários de pesquisa permite rememorar e resgatar o caminho percorrido. De tal forma, este artigo utilizou a produçáo de diários de pesquisa com 16 registros escritos pela pesquisadora.

Realizamos também a Entrevista de Explicitação (PASSOS; KASTRUP; ESCOSSIA, 2015), que consiste em perguntas semiabertas que poderiam ou não ser respondidas, assim como indicar outras perguntas a partir do desejo e da necessidade tanto das mulheres quanto da pesquisadora.

O terceiro instrumento foram as fotografias, que foram solicitadas a partir de verbos que conduziam as temáticas. A escolha dos verbos foi baseada na discussão sobre o conceito de Cotidiano. Heller (2000) indica que, na vida cotidiana, o genérico está contido em cada homem singular, mesmo que seus objetivos sejam particulares. Saraceno (1999) refere-se ao habitar, trabalhar e trocar ao indicar esferas de ação em reabilitação psicossocial. E, no campo da terapia ocupacional, valorizamos a maneira como são realizadas as Atividades de Vida Diária como uma teia que constrói rotinas, hábitos e surpresas no dia a dia. Sendo assim, optamos por três categorias de atividades genéricas - alimentar, falar e caminhar - para obter um olhar singular do que nos é coletivo.

\subsection{Análise dos dados}

A análise se deu por meio de uma análise qualitativa cruzando os dados obtidos por meio das entrevistas semiestruturadas, fotografias e diários de pesquisa com autores que dissertam sobre o cotidiano (CERTEAU; GIAR, 1996; KUJAWSKI, 1991) e sobre a pesquisa-intervençáo (BENEVIDES; PASSOS, 2009). $\mathrm{Na}$ análise do conteúdo, podemos encontrar respostas para as questôes formuladas e confirmar ou não hipóteses realizadas antes do trabalho. Além disso, diz respeito à descoberta do que está por trás dos conteúdos 
manifestos, indo além das aparências do que está sendo comunicado (MINAYO, 2001).

\subsection{Desenho da pesquisa}

Planejamos três encontros com cada participante:

$1^{\circ}$ encontro: Apresentação da proposta e convite da realização de três fotografias do seu dia a dia considerando os verbos indicados.

$2^{\circ}$ encontro: A participante deveria trazer as imagens registradas, e, com o objetivo de compreender melhor o processo, seria realizada a Entrevista de Explicitação.

$3^{\circ}$ encontro: Apresentação das fotografias, uma a uma, de modo aleatório, e conversa que teria como contorno os sentimentos proporcionados ao se olhar para as imagens. Ao final, as fotos seriam oferecidas para a participante, que poderia ficar com as quais desejasse.

\section{Resultados e Discussão}

Os resultados serão apresentados com a indicação das temáticas que mais chamaram a atenção das pesquisadoras no momento de análise dos dados. Apresentaremos dados que surgiram a partir dos três instrumentos utilizados. Para apresentação das temáticas, utilizamos verbos nos subtítulos que condensam os efeitos observados tanto sobre a pesquisadora quanto sobre as mulheres participantes, além dos três verbos que serviram de guia para orientar as fotografias.

Os trechos dos diários de pesquisa estão grafados em itálico, assim como algumas falas das mulheres, e têm o objetivo de exemplificar ou presentificar a experiência da pesquisadora e das mulheres no decorrer da pesquisa.

\subsection{O pesquisador e suas implicações}

Movimentar-se, conhecer e vincular, convidar:

[...] o mapa é aberto, é conectável em todas as suas dimensôes, desmontável, reversível, suscetível de receber modificaçôes constantemente. Ele pode ser rasgado, revertido, adaptar-se a montagens de qualquer natureza, ser preparado por um indivíduo, um grupo, uma formação social [...] (DELEUZE; GUATARRI, 2000, p. 22).

Foi possível observar que cada ida a campo exigiu redesenhar o "mapa metodológico", pois os acontecimentos exigiram um deslocamento da pesquisadora e das proposiçóes.

Quando projetamos uma pesquisa ela vem de maneira idealizada, como qualquer outro projeto que fazemos na vida, e ao nos depararmos com a realidade começamos a reconstrui-lo e adaptá-lo (ASSIS, 2013).

Em uma pesquisa qualitativa que se propóe também a ser uma intervenção, é preciso o tempo todo estar atento aos sinais do corpo, da fala, e aberto a modificaçóes, fundir o corpo de pesquisador com o de "objeto pesquisado" (LIBERMAN; LIMA, 2015).

\begin{abstract}
Eu já tinha uma história com cada destas duas mulheres, Fabiana e Eunice, construida no projeto de extensão. Também estive com elas no Grupo de Mulheres por um semestre juntamente com colegas do módulo Trabalho em Saúde sendo que uma de minhas tarefas neste grupo era buscar, insistir e persistir em levar Dona Eunice até o espaço onde esse acontecia. Ela, sempre muito calada, sem ânimo, muitas vezes recusou minha visita. Eu não desisti dela, e nem o Grupo, assim, aos poucos nos aproximamos e ela começou a efetivar sua presença. Enquanto isso, Fabiana ainda era acompanhada em casa por alunas da TS que tinham como objetivo inserir Fabiana no Grupo de Mulheres (ASSIS, 2013).
\end{abstract}

Ao longo do ano de 2012, a pesquisadora pôde conhecê-las e, aos poucos, construir uma relaçáo em que a comunicação era feita por meio de trocas de sorrisos.

Quando olho para os rumos que esta pesquisa tomou, fica clara a importância de um vínculo pré-estabelecido quando se vai oferecer uma proposta como a minha, na qual me convido a entrar na casa da pessoa e conhecer seu cotidiano, enquanto ela precisa olhar para si mesma e sua vida pelas lentes de uma câmera (ASSIS, 2013).

Os trechos do diário de pesquisa indicam a implicação da pesquisadora, que era anterior à pesquisa. Esse dado precisa ser considerado, pois afeta o desenvolvimento do trabalho e a análise dos dados. Na maior parte das pesquisas qualitativas, considera-se que o pesquisador não é neutro e que sua ação afeta o campo de pesquisa. Essa situaçáo náo prejudica a pesquisa desde que seja reconhecida e considerada como parte dela (PAULON, 2005).

Nascimento e Coimbra (2008) indicam que, na pesquisa-intervenção, as noçôes de sujeito e objeto, de pesquisador e de campo de pesquisa são colocadas em análise, criando um plano de imanência, no 
qual as práticas produzem tanto os sujeitos quanto os objetos, os pesquisadores e o campo.

Sendo assim, deve-se:

Defender que toda pesquisa é intervenção e exige do cartógrafo um mergulho no plano da experiência, lá onde conhecer e fazer se tornam inseparáveis, impedindo qualquer pretensão à neutralidade ou mesmo suposição de um sujeito e de um objeto cognoscentes prévios à relação que os liga [...] (PASSOS; BARROS, 2015, p. 30).

Podemos pensar que a pesquisa-intervenção que acontece no domicílio do sujeito pesquisado tem um elemento de intimidade que pode constranger tanto o sujeito pesquisado quanto o pesquisador, o qual, neste caso, sente-se confortável por já conhecer as mulheres. Nesse sentido, podemos citar Capozzolo, Casetto e Henz (2013), que trazem diversas consideraçóes sobre o deslocamento da prática de cuidado e de formaçáo de um ambiente dominado pelo profissional (ou docente, ou estudante) tal como um consultório ou uma sala de aula para uma prática na rua, no território, nas casas. Nesses locais, a relação modifica-se de diversas formas. Pode ficar mais horizontal ou gerar uma verticalidade invertida: quem manda é o dono da casa. Qualquer que seja a modificação, ela deve ser considerada na análise da pesquisa. No caso aqui descrito, a pesquisadora estava sensível a esse deslocamento, percebendo sua proposta como "delicada".

Outra análise, não excludente, é a de que a própria proposta, ao tratar da vida cotidiana, trazia um elemento de intimidade. A pesquisadora náo estava lá para fazer um atendimento, para tratar de assuntos de saúde. Nesse sentido, podemos fazer um paralelo com abordagens não convencionais e sua difícil penetração nos ambientes dominados pelas práticas médicas. A noção de saúde-doença, atrelada aos sintomas, a exames laboratoriais e a medicamentos, indica um movimento de medicalizaçáo da vida e a dificuldade de ampliar os recursos de intervençáo (CAPONI et al., 2010). Podemos levantar a hipótese de que aí resida uma das dificuldades de reconhecimento e de ampliaçáo do próprio campo de atuação da terapia ocupacional.

Outras cenas, que também se referem à relação pesquisador-pesquisado e suas modalidades, estão apontadas neste trecho:

Eu e Dona Eunice sorrimos muito uma para outra, eu falo muito e ela pouco, mas de repente um assunto lhe agrada e ela comanda nossa conversa. Nossa relação me toca de muitas maneiras, vi nela uma avó, uma paciente, uma amiga e a mim mesma (ASSIS, 2013).

Aqui podemos citar o conceito clássico de contratransferência e a importância de esta ser reconhecida no contexto da pesquisa-intervençáo. Rossi e Passos (2014), ao estabelecerem relaçóes entre a análise institucional e a pesquisa-intervenção, indicam que esse conceito foi deslocado do subjetivismo da relação dual inerente ao jogo transferencial para uma dinâmica coletiva-institucional, na qual todos os atores estão atravessados por diversos vetores que devem fazer parte da análise da implicação, sexo, raça, condição social, entre outros. Assim, com os autores Lourau e Guattari, os conceitos de transferência e contratransferência foram substituídos pelos conceitos de implicação e transversalidade.

No caso da pesquisa, podemos perguntar quais são os vetores que atravessam essa relação: a diferença de idade, de posição social, as posiçóes ocupadas por cada ator e como estes atuam no próprio processo de pesquisar. $\mathrm{O}$ trecho a seguir também se refere aos lugares ocupados:

O marco de nosso vínculo se deu em um dia de extremo calor em Santos, quando voltávamos do Grupo de Mulheres e eu fui acompanhá-la do ônibus até sua casa. Os passos eram lentos, mas de repente ela avistou seu ex-marido na porta de sua casa, que ainda estava longe, e ela com medo que ele fosse embora disse "...menina! Corre atrás dele e diz que eu já estou indo, ele não pode ir embora sem me ver!" e lá fui eu largando Dona Eunice no caminho para correr atrás de seu ex-marido. Quando voltei a encontrá-la e disse que ele estava esperando, um sorriso se abriu e pela primeira vez ela pegou em minha mão para que fossemos andando até sua casa, enganchadas uma na outra (ASSIS, 2013).

Percebemos que a relação estabelecida propicia o surgimento de demandas variadas. No caso da pesquisadora, o exercício de escrever no diário de pesquisa tornou-a mais sensível e perceptiva aos seus próprios sentimentos. Essa percepção foi importante para mantê-la no enquadre da pesquisa.

Outro aspecto relevante foi a proposta da atividade. Atividades são intrínsecas à relação constitucional da função terapêutica da terapia ocupacional, inscrevem-se no núcleo central do processo e não se separam dele por serem constituintes deste e por criarem a mobilidade nos seus campos de ação, o que inclui promover e ampliar formas de viver o dia a dia em diferentes situaçôes e condições (MAXIMINO; TEDESCO, 2016). Propor uma atividade em terapia ocupacional é tarefa que exige cuidado e delicadeza. 
A primeira a quem fiz convite foi Fabiana, durante o Grupo de Mulheres. Depois, por meio de uma conversa telefônica marcamos o dia e horário, lembro me de Fabiana dizendo: "Ah, pode virsim que eu participo, vai ser legal ajudar vocês" (ASSIS, 2013).

A expressão "vocês", referindo-se aos trabalhos e pessoas vinculadas à universidade, indica que a instituição deixou nesta participante uma marca importante que facilitou a aceitação da proposta.

Éramos como uma entidade - a Universidade. Percebi também, que aquilo não seria ruim para a minha relaçâo com ela, ao contrário, ela sempre relatava: "[...] o pessoal da faculdade é muito bom pra mim, me colocaram pra fora de casa" (ASSIS, 2013).

Ao final de cada de semestre, com a troca do grupo de alunos, há um receio de que haja quebra do vínculo e um questionamento sobre a validade do trabalho e a possibilidade de estarem "usando" as pessoas para aprender. Os docentes que permanecem no campo e o vínculo institucional, na maioria dos casos, criam continência suficiente para a continuidade do trabalho. Outro aspecto interessante trazido pela fala da participante é a inversão das posiçóes "...pode vir...vai ser legal ajudar vocês”. A participaçấo na pesquisa parece gerar empoderamento. Fabiana, agora, de certa forma, faz parte da universidade, é ativa, e náo apenas alvo do cuidado dos profissionais.

\subsection{Os encontros e o processo de pesquisar-intervir}

\subsubsection{Narrar}

$O$ encontro foi longo, com vários momentos de silêncio e outros de muito diálogo. A mãe retomou a história do adoecimento da filha. $E$ dali em diante Fabiana também foi contanto momentos de sua vida, contou sobre assuntos pessoais que me surpreenderam, não pelo conteuido, mas por perceber que o vinculo estava ali construido. Quando sua mãe foi buscar cafée bolo ela me perguntou se eu namorava, e começou a contar a sua trajetória amorosa (ASSIS, 2013).

Fabiana tinha uma vida como qualquer jovem de 26 anos: trabalhava, saía e namorava, até o dia em que, após a ingestáo de um lanche, começou a sentir-se mal. Foi hospitalizada e relata que sentia dores no corpo todo e um cansaço muito grande, sendo internada Unidade de Terapia Intensiva (UTI). Ninguém soube explicar o que, de fato, aconteceu; sabe-se que, após dois meses de UTI e duas paradas cardíacas, ela retornou do quadro. Porém, quando acordou, a vida já não era mais a mesma.

Fabiana dizia:

Aquele foi um tempo muito dificil, minha mente sabia que era eu, mas eu não conseguia olhar para mim e ver eu mesma. Fiquei um ano sem andar, sem falar, minha mãe fazia tudo por mim, a gente esperou um tempo pro meu namorado me ver, pra não assustar com a cara inchada, o corpo torto da sequela, esperamos quando eu já estava conseguindo sentar, mas eu não falava muito por causa que ainda tava com a traqueostomia. Só lembro que quando ele me viu começou a chorar, ficou em choque e foi embora, depois não voltou mais.

Contar novamente sobre seu adoecimento $e$ sobre a nova vida que teve de aprender a viver foi reencontrar-se com conflitos e vivências, mas de um outro lugar, dando novos significados às experiências. $O$ encontro foi marcado por fragmentos de uma história, e dali outra história também começou a ser tecida por nós em um recontar (ASSIS, 2013).

O processo de narrar a própria experiência possibilita ao sujeito reconstruir sua trajetória e lhe oferecer novos sentidos, estabelecendo uma relação dialética entre experiência e narrativa, mediada pelos processos reflexivos [...] (CUNHA, 1997 apud ALBUQUERQUE et al., 2010).

Falamos muito sobre sua rotina, seus afazeres, $e$ seus jeitos de fazer. Percebo que desde o primeiro encontro, mesmo antes de tirarmos as fotografias, já falávamos dos três verbos apresentados Caminhar, Alimentar e Falar - afinal, falar da vida não é falar de cotidiano? (ASSIS, 2013).

\subsubsection{Fazer, olhar e acompanhar}

Quando the apresentei o projeto, a ideia das fotos, ela me perguntou: "mas de mim? Eu tenho que aparecer? Tô velha!" Eu a provoquei dizendo que ela não precisaria aparecer, mas que as fotos eram sobre o cotidiano dela e [...] Como saberíamos que era dela se ela não aparecesse? (ASSIS, 2013).

Aqui podemos pensar sobre o manejo do terapeuta ocupacional ao fazer uma proposição. A pesquisa-intervençáo tem a característica de produzir um acontecimento, e, neste caso, a proposta e o jogo com a pesquisadora-terapeuta buscavam ampliar a possibilidade de presença na atividade e do olhar para si mesma, assim como também dar um lugar 
de existência para "a velha", contrapondo-se à ideia de que esta deveria "sair de cena".

Foi tudo rápido, ela estava sozinha tomando café preto e fumando, a televisáo ficou ligada, mas ela aceitou a pesquisa e me disse que falaria com sua filha para tirar as fotos. Antes da despedida ela disse: "olha que bom, terça e quinta a Ângela vem e agora você vai vir na quarta de manhä, a tarde tem Grupo de Mulheres e ai tem os médicos, os exames, vou ficar com a semana ocupada" (ASSIS, 2013).

Mais que participar de um projeto de pesquisa, o que valia era que o projeto iria dar à Eunice menos um dia de solidão. Nesse momento, o recurso ou a atividade não era o que lhe saltava aos olhos, mas a companhia, preenchendo seus dias e incidindo sobre seu cotidiano. E aqui está uma questão para o ato de pesquisar: não é possível conhecer o cotidiano dessas mulheres como algo que exista a priori, porque estes já estavam sendo modificados pela própria pesquisa.

Liguei para D. Eunice para saber como ela estava lidando com as fotos, ela disse que não estava conseguindo tirá-las, que sua filha trabalha e estava difícil fazer sozinha. Decidi fazer uma nova proposta e fizemos nosso segundo "primeiro encontro", sugeri a ela que tirássemos as fotos juntas e que não precisariam ser apenas três encontros, mas quantas vezes fossem necessárias (ASSIS, 2013).

Com Eunice, a programação precisou ser modificada, pois o plano de três encontros não seria suficiente para uma experiência satisfatória para ela e para mim. Percebemos que era preciso mais tempo para que as fotos pudessem ser tiradas da maneira que gostaríamos, bem como oferecer mais tempo de companhia durante o processo terapêutico. Foi um passo importante para a continuidade do trabalho. O fazer só ganharia sentido se fosse um fazer junto. Eunice aceitou a nova proposta e, dessa vez, pareceu mais animada com as fotos:

[...] bom né? Você tira as fotos que eu pedir, vem aqui, fica comigo e fazemos o trabalho.

\subsubsection{Fotografar: modos de fazer}

No segundo encontro, o que esperávamos era receber as fotos em um dispositivo móvel e realizar a entrevista. Durante a pesquisa sobre a efetividade do recurso terapêutico, foi preciso estar aberto a compreender de que formas o sujeito o utilizou e a apreender que efeito o recurso proposto produziu no sujeito e na relação triádica. O que ocorreu no segundo encontro revela que a proposição feita a cada participante pode ser a mesma, mas só terá função e significado quando cada um "burlar" as regras para fazer à sua maneira, como as duas participantes fizeram: Eunice solicitando maior tempo de encontros e Fabiana procurando novas formas de comunicar, como a internet.

Essa invenção do cotidiano se dá graças ao que Certeau chama de "artes de fazer", "astúcias sutis", "táticas de resistência" que vão alterando os objetos e os códigos, e estabelecendo uma (re) apropriaçáa do espaço e do uso ao jeito de cada um [...] (DURAN, 2007, p. 119).

Fabiana tem forte ligação com redes sociais e uso da internet, mas relata náo usar tanto dispositivos móveis para fotografar quanto gostaria. Ela tirou as fotos rapidamente e foi possível perceber a mobilização gerada pelas imagens. Já no primeiro encontro, ao apresentar o projeto, ela relatou ideias do que fazer e de onde tirar as fotos, sabia que iria acionar sua irmã, sua mãe e seu professor de natação.

\subsubsection{Caminhar}

Do verbo caminhar, Fabiana optou por retratar a Lagoa da Saudade, um lugar que ela gostava muito, mas não visitava há tempo. Convocou sua irmã para que a levasse até lá para fazerem uma caminhada.

Fabiana conta que sua irmã sempre fazia questão de sua participação em passeios e a incentivava para que saísse mais.

$\mathrm{Na}$ Figura 1, pode-se visualizar a selecionada para caminhar.

Ao utilizar a entrevista semiaberta no segundo encontro, ela contou que tirou a foto por ter saudade de caminhar. Relatou não gostar do bairro onde mora e que, apesar de ter saído muito nova do Morro, onde morava antes e onde fica a Lagoa, preferia este bairro ao seu local de moradia atual. O caminhar despertou reflexóes sobre seu cotidiano, não só para além do simples ato de caminhar, mas também por onde caminhamos, onde desejamos estar.

O segundo encontro fluiu de maneira mais rápida. Fabiana havia adicionado a pesquisadora à sua rede social e enviado as fotos tiradas, possibilitando, assim, que estas fossem levadas já reveladas. Com as outras fotos também foi desta maneira, ela se organizou e mobilizou pessoas para sua atividade.

Ao contrário da outra participante, que exigia uma relação presencial para a realização da atividade de fotografar, Fabiana dedicou mais tempo para se olhar e falar sobre as fotografias. 


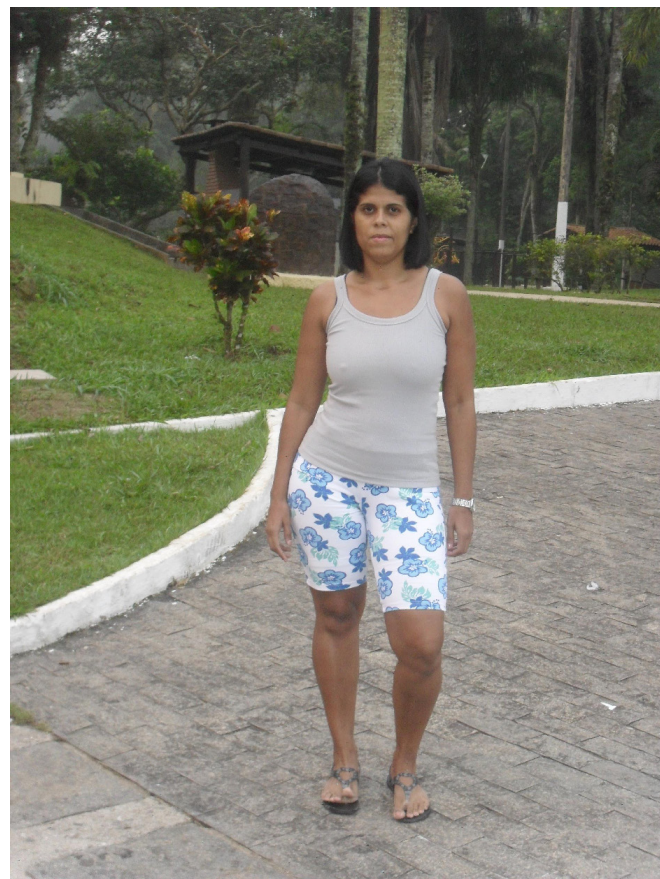

Figura 1. Na Lagoa da Saudade.

Novamente, ela me mostrou o seu próprio jeito de participar e criar aquela pesquisa comigo, era bom saber que ela se sentia à vontade para interferir (ASSIS, 2013).

Com Eunice, foi preciso colher a nova pista que ela havia dado via telefone: a dificuldade em tirar as fotos. Ela dependia de uma série de movimentos e apoios para chegar até o portáo e abrir a porta. Apesar de ter uma bengala, preferia apoiar-se no seu varal. E foi essa a cena que Eunice quis registrar para a pesquisa.

Enquanto vinha pelo corredor, me perguntou onde estava a máquina, eu disse que estava na bolsa e ela disse "então tira ué, já vamos tirar aqui mesmo, com o meu varal né?". Ela ainda questionou se aquilo valia como caminhar já que era no corredor da casa, e eu perguntei "mas Dona Eunice por onde é que a senhora anda? E se não tivesse o varal, já pensou?" ela então utilizou uma expressão que usava com muita frequência: "Que horror!! É feio né, horrivel, mas saio de casa e abro o portão porque tem o varal aqui".

$\mathrm{Na}$ Figura 2, vê-se a fotografia do caminhar de Eunice.

Inicialmente, o verbo caminhar foi um grande desafio para Eunice: como falar de algo tão difícil no seu cotidiano? Sua dificuldade no caminhar devido

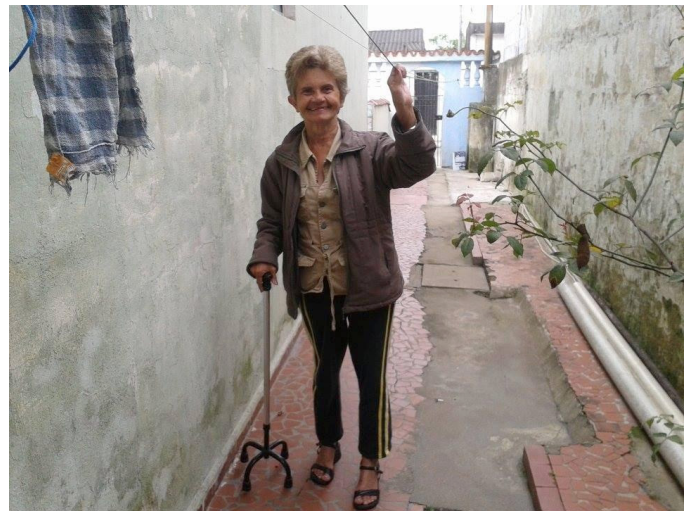

Figura 2. Eunice e seu varal.

a problemas de saúde vem lhe privando de muitas coisas, pois fez uma mulher que saía e sentia-se livre tornar-se dependente de outras pessoas e de objetos para se locomover.

No primeiro momento da oferta do projeto, Eunice disse que não caminhava. Eu lhe respondi que não precisava ser no sentido da atividade fisica, mas do se deslocar, mesmo que fosse dentro de sua própria casa. No momento da devolutiva ela escolheu a foto em que estava sorrindo como a melhor foto, pois não estava parecendo "morta" (ASSIS, 2013).

É na terapia ocupacional que, muitas vezes, essas pessoas sáo solicitadas a fazer algo pela primeira vez ... A escolha de projetos de atividades permeia diferentes dimensóes [...] (MARCOLINO, 2003, p. 56).

A impossibilidade de caminhar transformou-se em uma fotografia de um caminhar possível, adaptado, escorado pelo varal. A escolha dela por essa foto pode tê-la ajudado a perceber uma estratégia inventada por ela para lidar com suas dificuldades no seu dia a dia.

\subsubsection{Alimentar}

Com relaçáo à foto do verbo alimentar, Eunice revelou o desejo de tirar com sua colega que fazia o almoço para ela. A pesquisadora a ensinou a fotografar com o celular e, afirmando sua expectativa de ver as fotos no próximo encontro, estimulou o protagonismo da participante.

$\mathrm{Na}$ terceira visita, a pesquisadora perguntou sobre as fotos que ela havia ficado incumbida de tirar - verbo alimentar - e ela contou alegremente que havia cumprido com o combinado. E perguntou: "achou que eu não ia fazer, né?". Após olharem as fotos que haviam sido tiradas na semana anterior, foi 
utilizada a entrevista como ferramenta para a reflexão sobre o processo, fazendo emergir pequenos desejos, como o de tirar uma foto com alguém querido.

E se o terapeuta não é capaz de olhar, mas apenas de ver, estará apto somente a fornecer diagnósticos para determinadas situaçóes e, a partir deles, propor um plano de tratamento previamente estabelecido. Náo será capaz de entrar num espaço de troca com seu usuário, no qual este, como agente do processo, colocará constantemente enigmas para seu terapeuta [...] (LIMA, 2004, p. 45).

Com Fabiana a proposta com o verbo Alimentar foi mais literal, o tradicional almoço está ali na foto, mas... diz Fabiana: - Tirei assim, porque eu sempre como sozinha, aqui em casa cada um come na sua hora, minha máe deixa pronto e cada um pega o seu. Não ligo de comer sozinha, até prefiro, o difícil é deixar o prato assim, tem que ser colorido né. Desde que fiquei doente tem que comer muito regrado, todo mundo fica de olho no que eu como. Eu náo gosto de comer salada, verdura, fruta, mas fazer o que, é assim que tem que ser (ASSIS, 2013).

$\mathrm{Na}$ Figura 3, segue a fotografia da alimentação para Fabiana.

Ela relatou que foi a foto que menos a motivou, pois alimentar-se não lhe trazia mais prazer; fazia apenas parte de uma rotina que ela devia cumprir.

A perda do cotidiano, com a sua sequência, as suas formas, cores e sabores peculiares, é o que de mais grave pode comprometer o destino do homem, bloqueando sua capacidade de absorver a circunstância [...] (KUJAWSKI, 1991, p. 36).

\subsubsection{Falar}

Meus encontros com Fabiana foram marcados de muito falar, e para este verbo, ela decidiu me contar algo bom, que gostava em sua rotina: - Essa foto da natação foi meu professor quem tirou, eu descobri a natação e gostei muito. $E$ E único exercício que eu faço que gosto, se eu parar um dia com a fisioterapia e tudo mais, eu não vou parar com a natação (ASSIS, 2013).

$\mathrm{Na}$ Figura 4, a fotografia do que é falar para Fabiana.

É interessante notar que, apesar de não haver uma opção relacionada a alguma atividade sobre o que as participantes gostam de fazer, por exemplo, Fabiana encontrou na proposta uma oportunidade de dar visibilidade a algo importante em seu cotidiano: falar sobre aquilo que foi retratado na foto, a nataçáo e seu prazer.

Na Figura 5, trata-se do que seria falar para Eunice.

Eunice decidiu que a foto seria com a pesquisadora, que representava todos aqueles alunos e professores da universidade que iam à sua casa, que falavam com ela, mesmo quando ela não queria.

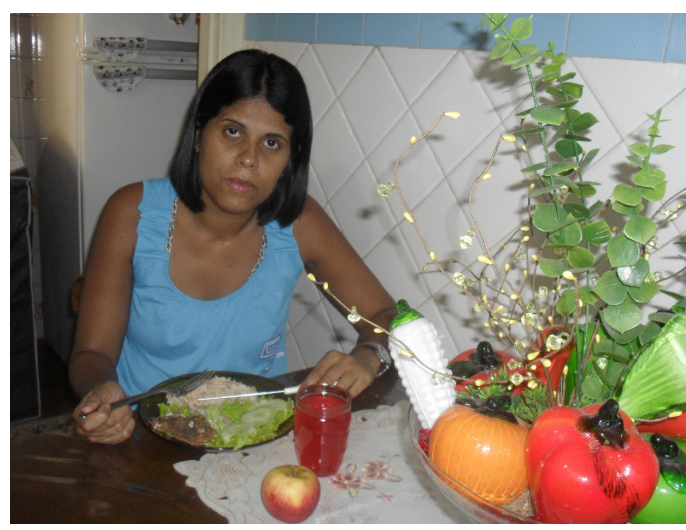

Figura 3. Fabiana e suas frutas.

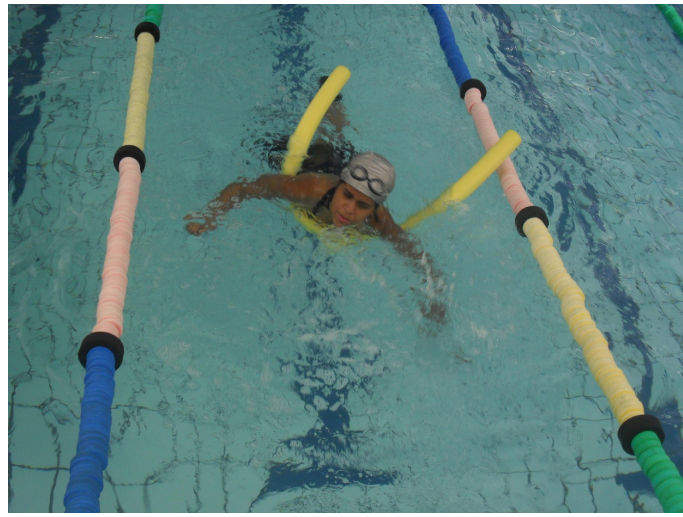

Figura 4. Conversa com a água.

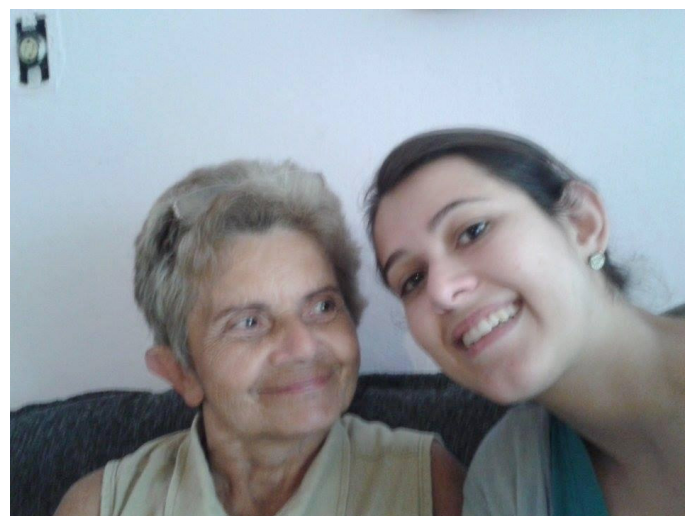

Figura 5. Sorrisos. 
Sabe, tinha dia que vocês vinham aqui e eu não queria nada com ninguém, mas mesmo assim era bom. Fui gostando da companhia, de falar com a moçada, é bom pra mim. Evocês são insistentes né, não desistem da gente, vinham mesmo depois que eu dizia não.

Em sua fotografia, assim como Fabiana, Eunice decidiu falar de algo que lhe agradava: a companhia e a conversa com todos aqueles da universidade que lhe ofereceram atenção e tempo. Foi uma fotografia espontânea a escolhida para aparecer no trabalho. Com Eunice, esses momentos espontâneos a libertavam do engessamento de seu dia a dia e permitiam movimentos novos para si, pequenas frestas pelas quais podíamos acessá-la.

É interessante notarmos que o verbo falar suscitou associaçóes com atividades e relaçóes consideradas importantes para as duas mulheres e que as imagens fotografadas não foram tão literais quantos as primeiras. Talvez, nesse momento do trabalho, elas estivessem mais seguras e à vontade para arriscar outras aberturas. Podemos imaginar que, se a proposta continuasse, o trabalho terapêutico poderia seguir cada vez mais criativo.

Nesse sentido, assim como o artista, o terapeuta ocupacional também precisa se "ocupar" da percepção e buscar nas imagens mais cotidianas e mais comuns aquilo que nelas há de inusitado, de novo, de diferente, de interessante, de singular. Para isto talvez seja preciso pensar, agir e olhar no cotidiano como faria um estrangeiro: estranhar e se encantar com cada nova revelação [...] (LIMA, 2004, p. 46).

Quando eu disse para Eunice que a pesquisa havia terminado e eu iria embora e perguntei a ela sua opinião sobre o projeto, mais um desejo surgiu. Decidimos que eu iria na semana seguinte apenas para nos despedirmos. Ela ainda me falou: "Ah eu estou me sentindo viva, foi bom ter companhia, foto é legal! Achei que não dava mais para tirar foto porque estou velha, acabada, mas até que dá" (ASSIS, 2013).

Com Fabiana, o terceiro encontro foi, de fato, o último. Nesse dia, ela estava aguardando na porta e conversamos sobre o que havia feito. Conversamos sobre os motivos de Fabiana não gostar de fotos de corpo inteiro e sair tão pouco, sobre relacionamentos amorosos e familiares. A cada foto que olhávamos surgia algo para além delas, os sentidos, os caminhos do passado, do futuro e do presente.

\section{Conclusão}

A fotografia também se apresentou como importante recurso a ser utilizado em terapia ocupacional, como proposta de intervençáo que oferece diferentes possibilidades de olhar e experimentar o cotidiano de um modo ampliado e que propóe novas experiências. A utilização de verbos como guia para as fotografias mostrou-se eficaz, funcionando como disparador de temáticas do cotidiano, ampliando a intervenção e abrindo espaços de discussão sobre o processo.

Ao final, percebemos que a pesquisa-intervenção permite que cada participante trace sua própria trajetória e dê visibilidade aos processos que estáo sempre em constante mudança. Podemos reafirmar o importante papel do terapeuta ocupacional na reinvenção de cotidianos, por meio do envolvimento e protagonismo nas atividades permeadas pela relaçáo, o que pode propiciar o empoderamento dos sujeitos acompanhados.

\section{Referências}

ALBUQUERQUE, V. S. et al. A narrativa da prática como uma estratégia de construçáo do conhecimento na formação superior em saúde. Educar em Revista, Curitiba, n. 2, p. 191-206, 2010.

ARAÚJO, L. F. S. et al. Diário de pesquisa e suas potencialidades na pesquisa qualitativa em saúde. Revista Brasileira de Pesquisa em Saúde, Vitória, v. 15, n. 3, p. 53-61, 2013.

ASSIS, C. A. R. Diário de pesquisa. [S.l.]: [s.n.], 2013. Arquivo pessoal.

BARROS, L. P.; KASTRUP, V. Cartografar é acompanhar processos. In: PASSOS, E.; KASTRUP, V.; ESCÓSSIA, L. (Ed.). Pistas do método da cartografia: pesquisa-intervençáo e produção de subjetividade. Porto Alegre: Sulina, 2010. p. 52-75.

BARTHES, R. A câmara clara. Rio de Janeiro: Nova Fronteira, 1980.

BENETTON, M. J. Trilhas associativas, ampliando subsidios metodológicos à clínica da terapia ocupacional. Campinas: Arte Brasil, 2006.

BENEVIDES, R.; PASSOS, E. A cartografia como método de pesquisa-intervenção. In: PASSOS, E.; KASTRUP, V.; ESCÓSSIA, L. (Ed.). Pistas do método da cartografia. Porto Alegre: Sulina, 2009. p. 17-30.

CAPONI, S. et al. (Ed). Medicalização da vida: ética, saúde pública e indústria farmacêutica. Palhoça: Editora Unisul, 2010.

CAPOZZOLO, A. A.; CASETTO, S. J.; HENZ, A. O. (Ed.). Clínica comum: itinerários de uma formação em saúde. São Paulo: Hucitec Editora, 2013.

CERTEAU, M.; GIAR, L. A invenção do Cotidiano: 2. Morar e Cozinhar. Petrópolis: Vozes, 1996.

DELEUZE, G.; GUATARRI, F. Mil platôs: capitalismo e esquizofrenia. São Paulo: Ed. 34, 2000. 
DURAN, M. C. G. Maneiras de pensar o cotidiano com Michel Certeau. Revista Diálogo Educacional, Curitiba, v. 7, n. 22, p. 115-128, 2007.

FRANÇA, A.; SHIMANSKI, É. Mulher, trabalho e família: uma análise sobre a dupla jornada feminina e seus reflexos no âmbito familiar. Emancipaçâo, Ponta Grossa, v. 9, n. 1, p. 65-78, 2009. http://dx.doi.org/10.5212/ Emancipacao.v.9i1.065078.

HELLER, A. O cotidiano e a história. São Paulo: Paz e Terra, 2000.

KASTRUP, V. O funcionamento da atenção no trabalho do cartógrafo. In: PASSOS, E.; KASTRUP, V.; ESCÓSSIA, L. (Ed.). Pistas do método da cartografia. Porto Alegre: Sulina, 2009. p. 32-51.

KUJAWSKI, G. M. A crise do cotidiano. In: KUJAWSKI, G. M. A crise do século XX. São Paulo: Ática, 1991. p. 31-61.

LIBERMAN, F. Delicadas coreografias: instantâneos de uma terapia ocupacional. São Paulo: Summus, 2008.

LIBERMAN, F.; LIMA, E. M. F. A. Um corpo de cartógrafo. Interface - Comunicação, Saúde, Educação, Botucatu, v. 19, n. 52, p. 183-193, 2015. http://dx.doi. org/10.1590/1807-57622014.0284.

LIMA, E. M. F. A. A análise de atividades e a construção do olhar do terapeuta ocupacional. Revista de Terapia Ocupacional da Universidade de São Paulo, São Paulo, v. 15, n.2, p. 42-48, 2004.

MACERATA, I. M.; SOARES, J. G. N.; RAMOS, J. F. C. Apoio como cuidado de territórios existenciais: atenção Básica e a rua. Interface - Comunicação, Saúde, Educação, Botucatu, v. 18, p. 805-1150, 2014. Suplemento 1 .

MARCOLINO, T. Q. Sobre reabilitar o que não se reabilita. Revista do Centro de Estudos de Terapia Ocupacional, São Paulo, v. 8, n. 8, p. 54-58, 2003.

MAXIMINO, V. S.; TEDESCO, S. Rotina, hábitos, cotidiano: do banal ao sutil no encantamento da vida. In: MATSUKURA, T. S.; SALLES, M. M. (Ed.). Cotidiano, atividade humana e ocupação: perspectivas da terapia ocupacional no campo da saúde mental. São Carlos: EdUFSCar, 2016. p. 123-146.
MINAYO, M. C. S. (Ed.). Pesquisa Social: teoria, método e criatividade. Petrópolis: Vozes, 2001.

NASCIMENTO, M. L.; COIMBRA, C. M. B. Análise de implicaçóes: desafiando nossas práticas de saber/ poder. In: GEISLER, A. R.; ABRAHĀO, A. L.; COIMBRA, C. M. B. (Ed.). Subjetividade, violência e direitos humanos: produzindo novos dispositivos na formação em saúde. Niterói: EDUFF, 2008. p. 143-153.

NEIVA-SILVA, L.; KOLLER, S. H. O uso da fotografia na pesquisa em Psicologia. Estudos de Psicologia, Porto Alegre, v. 7, n. 2, p. 237-250, 2002.

OSÓRIO, G. Possibilidades e limites da dança para o empoderamento de mulheres: um olhar da saúde coletiva. 2015. 145f. Dissertação (Mestrado em Ciências) - Universidade de São Paulo, São Paulo, 2015.

PASSOS, E.; BARROS, R. B. A cartografia como método de pesquisa-intervenção. In: PASSOS, E.; KASTRUP, V.; ESCÓSSIA, L. (Ed.). Pistas do método da cartografia: pesquisa-intervenção e produção de subjetividade. Porto Alegre: Sulina, 2015. p. 17-30.

PASSOS, E.; KASTRUP, V.; ESCÓSSIA, L. (Ed.) Pistas do método da cartografia: pesquisa-intervenção e produção de subjetividade. Porto Alegre: Sulina, 2015.

PAULON, S. M. A análise de implicação como ferramenta na pesquisa-intervenção. Psicologia \& Sociedade, Belo Horizonte, v. 17, n. 3, p. 18-25, 2005.

ROSSI, A.; PASSOS, E. Análise institucional: revisão conceitual e nuances da pesquisa-intervenção no Brasil. Revista EPOS, Rio de Janeiro, v. 5, n. 1, p. 156-181, 2014. Disponível em: <http://pepsic.bvsalud.org/scielo. php?script=sci_arttext $\&$ pid=S2178-700X20140001000 09\&lng=pt\&nrm=iso $>$. Acesso em: 24 abr. 2017.

SARACENO, B. Libertando identidades: da reabilitação psicossocial à cidadania possível. Rio de Janeiro: Té Corá, 1999 .

SOARES, V. M. N. Desigualdades na saúde reprodutiva das mulheres no Paraná. Revista Brasileira de Epidemiologia, São Paulo, v. 10, n. 3, p. 293-309, 2007. http:// dx.doi.org/10.1590/S1415-790X2007000300002.

SONTAG, S. A caverna de platão. In: SONTAG, S. Ensaios sobre fotografia. Rio de Janeiro: Arbor, 1981. p.11-35.

\section{Contribuição dos Autores}

Carine Abrahão Rodrigues Assis responsabilizou-se pelo desenvolvimento da pesquisa. Flavia responsabilizou-se pela orientação da pesquisa. Flávia Liberman e Viviane Santalucia Maximino responsabilizaram-se pela supervisão do trabalho em campo em todas as suas etapas. Todos os autores aprovaram a versão final do texto.

\section{Notas}

${ }^{1}$ Todos os procedimentos éticos necessários para a realização da pesquisa foram cumpridos, podendo ser acessado por meio do Comitê de Ética em Pesquisa sob o número CAAE 17008513.5.0000.5505. O material obtido é parte de um Projeto de Extensão, ou seja, de uma intervenção. O texto foi apenas apresentado como trabalho de Conclusão de Curso da autora Carine Abrahão Rodrigues Assis.

${ }^{2}$ Utilizaremos a palavra "Cotidiano" gravada em letra maiúscula para indicar o conceito e em letra minúscula - cotidiano - para se referir à ideia de dia a dia. 
${ }^{3}$ Projeto de Extensão desenvolvido na UNIFESP, campus Baixada Santista, que visa ao acompanhamento interdisciplinar a mulheres em situação de vulnerabilidade na regiáo da zona noroeste de Santos.

${ }^{4}$ Macerata et al. (2014, p. 922), utilizando o conceito de território existencial em Guattari, dizem que este "[...] não se refere a um território como um ponto em um mapa, estático e já delimitado em si. Mais que uma delimitação espacial, um território existencial é uma localização espaço-temporal. Ele se define a partir de uma localização espacial que é configurada no tempo, ou seja, ele é um território em processo, em constante processo feitura".

${ }^{5}$ Alerta-se que a realidade será sempre recortada pelo olhar de quem fotografa e/ou de quem escolhe o que e como será fotografada cada cena.

${ }^{6}$ NAPS I: Núcleo de Apoio Psicossocial que oferece atenção em saúde mental à população da região. Arte no Dique: organização não governamental que promove atividades culturais e artísticas para a comunidade. PSF Jardim Castelo: Unidade de Estratégia Saúde da Família.

${ }^{7}$ Módulo Trabalho em Saúde (TS): trata-se de um eixo comum a todos os cursos da saúde da UNIFESP, Baixada Santista, que tem como objetivo propiciar ao estudante a compreensão das diversas concepçôes e múltiplas dimensôes envolvidas no processo saúde/doença/cuidado, de maneira a produzir uma análise crítica dos problemas de saúde da sociedade por meio de uma intervenção interdisciplinar.

${ }^{8}$ Utilizamos a expressão "construção de dados" no sentido descrito por Kastrup (2009, p. 33), quando diz que "[...] do ponto de vista dos recentes estudos da cognição numa perspectiva construtivista, não há coleta de dados, mas desde o início, uma produção de dados da pesquisa”. 